\title{
Bottlenose dolphin abundance in the NW Mediterranean: addressing heterogeneity in distribution
}

\author{
Jaume Forcada ${ }^{1, *}$, Manel Gazo $^{2}$, Alex Aguilar ${ }^{2}$, Joan Gonzalvo $^{2}$, \\ Mar Fernández-Contreras ${ }^{2}$
}

${ }^{1}$ British Antarctic Survey, Natural Environment Research Council, Madingley Road, Cambridge CB3 0ET, United Kingdom ${ }^{2}$ Department of Animal Biology (Vertebrates), Faculty of Biology, University of Barcelona, 08071 Barcelona, Spain

\begin{abstract}
Line-transect estimators were developed to assess abundance of coastal dolphins Tursiops truncatus and Stenella coeruleoalba encountered in low densities during aerial sighting surveys. The analysis improved on conventional approaches by objectively combining data from different species, survey areas and other covariates affecting dolphin detectability. Model selection and multimodel inference allowed robust estimates of precision in accounting for covariate selection uncertainty. These methods were used to estimate bottlenose dolphin abundance in NE Mediterranean waters that included a putative subpopulation in the Balearic Islands. Total abundance was estimated as 7654 (coefficient of variation, $\mathrm{CV}=0.47 ; 95 \% \mathrm{CI}=1608$ to 15766 ) and the abundance in inshore waters of the Balearic Islands varied from 727 (CV $=0.47 ; 95 \% \mathrm{CI}=149$ to 1481) dolphins in spring 2002 to $1333(\mathrm{CV}=0.44 ; 95 \% \mathrm{CI}=419$ to 2617$)$ dolphins in autumn 2002, with an average estimate of 1030 (CV $=0.35 ; 95 \% \mathrm{CI}=415$ to 1849). The results do not support an exclusively coastal Balearic Island subpopulation, but they strongly indicate that the islands contain critical habitats required for the conservation of the species. Given the observed decline of the species during the last few decades, conservation-oriented management should focus on reducing or eliminating adverse fishing interactions while key areas are protected from encroachment produced by human development.
\end{abstract}

KEY WORDS: Abundance · Conservation · Aerial survey · Availability bias · Balearic Islands · Balearic Sea · Bottlenose dolphin · Covariate analysis · Line transect · Tursiops truncatus

\section{INTRODUCTION}

The World Conservation Union (IUCN) periodically reviews the extinction risk of cetacean species worldwide (Reeves et al. 2003). The level of risk is determined with objective population-based criteria concerning abundance, trends, habitat fragmentation and geographic range (IUCN 2001), which rely on available data. In many species with coastal ranges, population size is not available or estimates lack rigorous statistical standards and the classification is either 'data deficient' or 'not evaluated'. This problem not only affects rare or poorly known species, but also the bottlenose dolphins Tursiops sp., which are amongst the most frequently encountered cetaceans in temperate and tropical latitudes of the world's oceans. In coastal bottlenose dolphins, the lack of data results from 2 main difficulties. First, the implementation of abundance estimation methods is complicated because distribution ranges can be relatively large or unknown, with dolphins occurring in clustered aggregations and in low densities. Second, there is seldom enough information on genetic identity and demographic isolation to identify subpopulations, which are the management units adopted for risk assessment under IUCN criteria. These difficulties have set back the conservation management of species with coastal ranges and there is a demand for reliable population assessments. 
The common bottlenose dolphin Tursiops truncatus occurs in populations that range in far offshore waters and others that are mostly or exclusively coastal, along the continents and around islands. In coastal populations, bottlenose dolphins live in a variety of habitats including bays, lagoons, estuaries and lower reaches of rivers (Wells \& Scott 2002). Because of this proximity to land, many population assessments are based on a mark-recapture analysis of photo-identification data (e.g. Wells \& Scott 1990, Williams et al. 1993, Wilson et al. 1999). However, those assessments only refer to photo-identified populations, which may not be subpopulations in the IUCN sense (e.g. Hansen \& Defran 1990, Carretta et al. 1998, Fortuna et al. 2000). Coastal bottlenose dolphins have seasonal migrations, yeararound home ranges, periodic residency and a combination of occasional long-range movements and repeated local residency (cf. Wells \& Scott 2002).

Line-transect methods (Buckland et al. 2001) via aerial sighting surveys provide a way of efficiently sampling coastal cetaceans. A small aircraft can be used to sample the coastal ranges where a subpopulation of interest is known to occur, and also sample peripheral areas buffering the subpopulation during seasonal movements. However, when subpopulations are small and distributions are clustered, aerial sighting surveys may only encounter a few groups. In this situation, conventional methods may not produce accurate and precise abundance estimates.

This article describes the implementation of linetransect estimators for aerial survey data that can combine in a flexible and objective way sightings of multiple species, geographic areas, seasons and sighting conditions to estimate abundance when sample size is small. These estimators were applied to the study of the bottlenose dolphin in the Balearic Islands, a putative subpopulation with seasonal movements and a probable exchange of individuals with a larger population in the Balearic Sea, NW Mediterranean. We describe the large-to-local scale survey design required to effectively account for the distribution range and seasonal changes of this subpopulation.

The analysis was motivated by the increasing exposure of bottlenose dolphins to human impact in the Mediterranean Sea. During the last few decades, adverse interactions with fisheries, prey depletion and pollution have severely reduced the size and geographical range of populations (Notarbartolo di Sciara et al. 2002). As a consequence, the species is currently considered as deserving 'special interest for conservation' under the European Union's habitats directive. Moreover, the current IUCN conservation action plan for cetaceans has strongly recommended the estimation of bottlenose dolphin subpopulation sizes in the Mediterranean Sea (Reeves et al. 2003). The present paper responds to this recommendation with the first comprehensive assessment of the distribution and abundance of bottlenose dolphins in the Balearic Islands and adjacent waters, a putative subpopulation considered to be among those best preserved in the Spanish Mediterranean (Blanco \& González 1992). In addition, it provides new analytical tools to enable similar exercises in other regions and species.

\section{MATERIALS AND METHODS}

Study area and allocation of survey effort. The study area was delimited by the Spanish/French border in the north, the offshore waters of the Gulf of Valencia in the south, the waters off eastern Minorca in the east and the mainland in the west. The study was on 2 different scales: a larger scale comprising the whole area (Fig. 1), and a smaller scale in regions where previous information suggested that local bottlenose dolphin subpopulations exist: the Balearic Islands and Cape Creus.

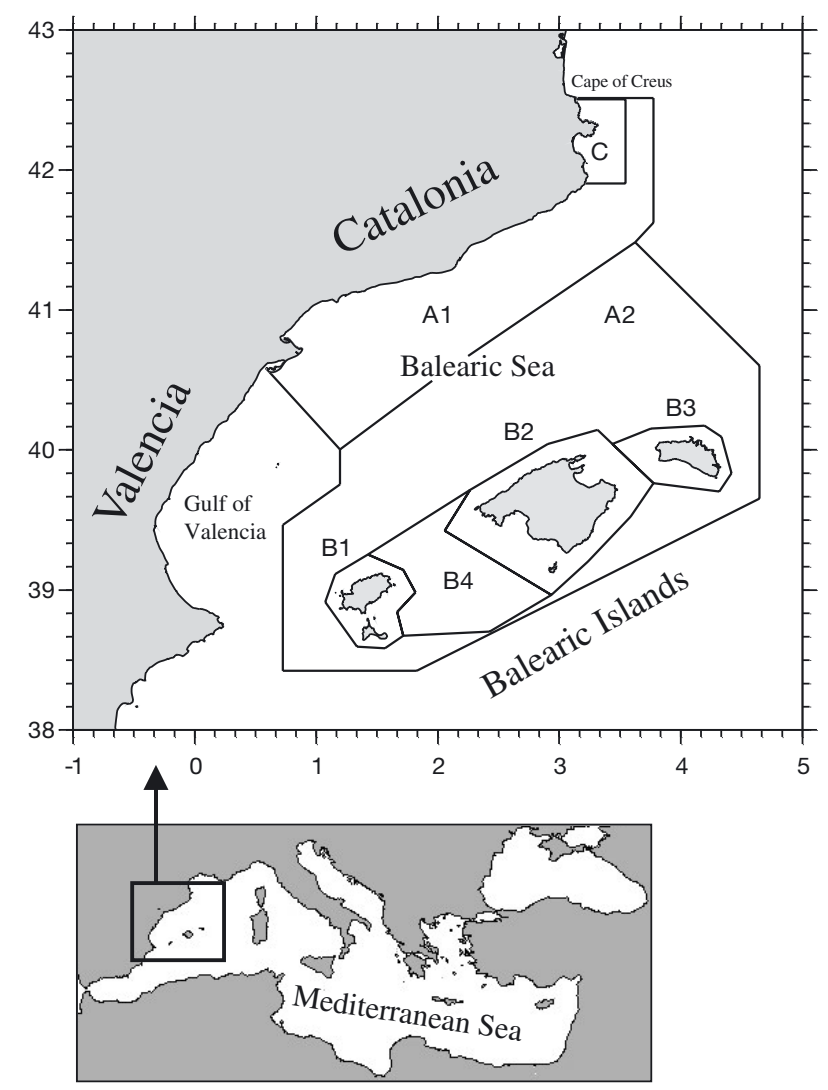

Fig. 1. Area surveyed, showing geographic strata delimited by continuous lines. Horizontal and vertical axes are degrees and minutes of latitude and longitude respectively. Positive latitudes are North, positive longitudes are East. A1: coastal Catalonia; A2: offshore Balearic Islands; B1 to B3: inshore Balearic Islands; B4: deep waters between 2 Balearic islands (details in 'Materials and methods') 
Table 1. Geographic strata, showing effective survey effort as a function of survey replicate. Areas labelled as in Fig. 1; -: replicates not surveyed

\begin{tabular}{|lrrcr|}
\hline Area & \multirow{2}{*}{ Area size } & \multicolumn{3}{c|}{ Effective effort $(\mathrm{km})$} \\
& $\left(\mathrm{km}^{2}\right)$ & Replicate 1 & Replicate 2 & Mean \\
\hline A1 & 24243.2 & 660.3 & 650.8 & 655.5 \\
A2 & 62170.7 & 1329.0 & - & 1329.0 \\
Total A & 86413.9 & 1989.3 & - & 1984.6 \\
B1 & 2903.4 & 397.6 & 390.9 & 394.3 \\
B2 & 6935.7 & 762.3 & 767.1 & 764.7 \\
B3 & 2238.7 & 448.0 & 440.9 & 444.5 \\
B4 & 6580.8 & - & 337.6 & 337.6 \\
Total B & 16658.6 & 1607.9 & 1936.5 & 1772.2 \\
C & 1993.5 & 303.7 & 331.5 & 317.6 \\
\hline
\end{tabular}

The larger area surveyed was divided into 2 strata, one comprising the coastal waters of Catalonia (Fig. 1: A1), the other the offshore waters of the Balearic Islands (Fig. 1: A2). At a local scale, Cape Creus was treated as a single stratum, centered at the cape (Fig. 1: C) and extending $25 \mathrm{~km}$ into offshore waters. The inshore waters of the Balearic Islands were divided into 4 strata: B1 comprising the islands of

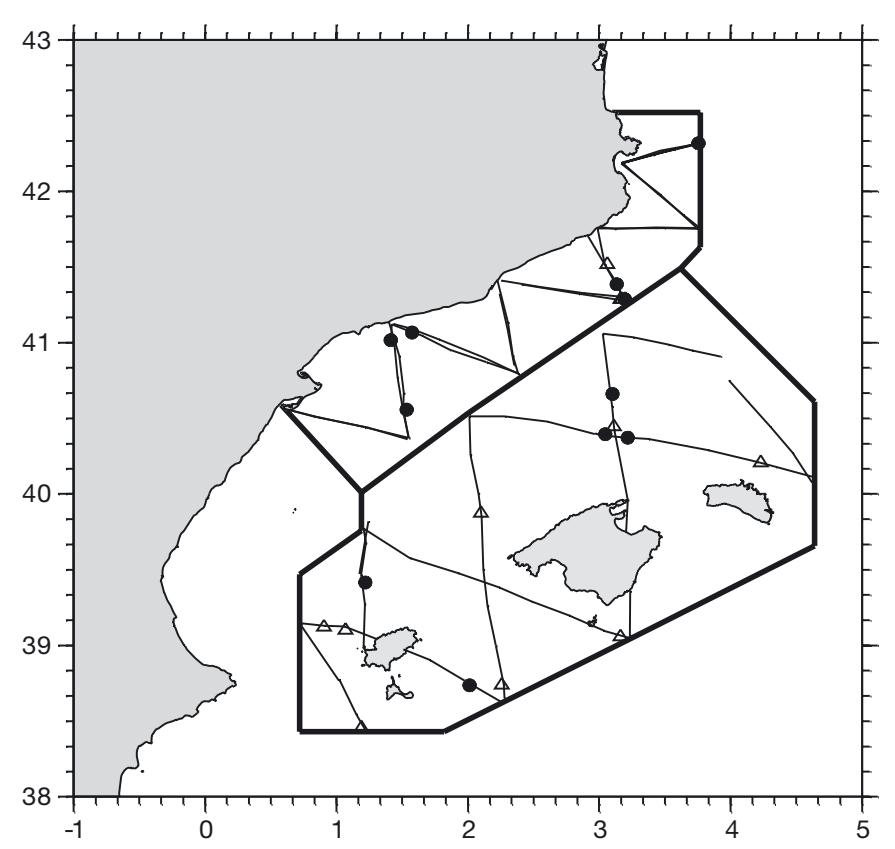

Fig. 2. Area surveyed for abundance of Tursiops truncatus and Stenella coeruleoalba, showing large-scale strata A1 (comprising inshore waters) and A2 (comprising offshore waters) delimited by bold continuous lines. Horizontal and vertical axes are degrees and minutes of latitude and longitude respectively. Positive latitudes are North, positive longitudes are East. Effectively surveyed transects are shown by thin continuous lines. $(\bullet)$ Bottlenose dolphin and $(\Delta)$ striped dolphin groups detected

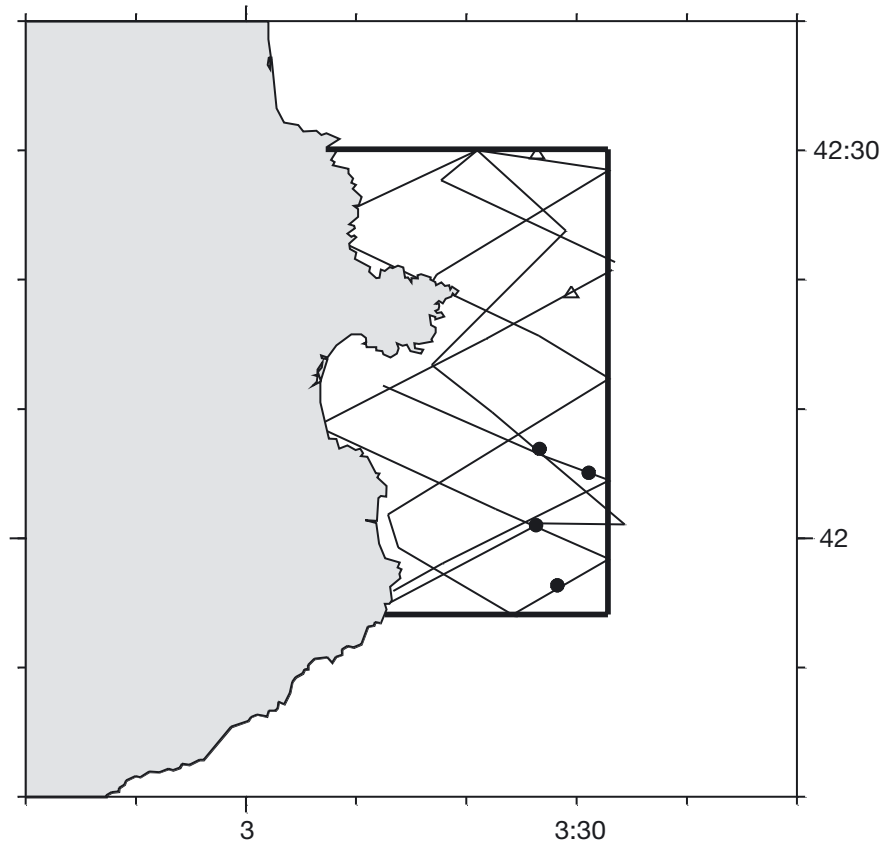

Fig. 3. Cap of Creus survey stratum (C in Fig. 1) surveyed for abundance of Tursiops truncatus and Stenella coeruleoalba delimited by bold continuous lines. Horizontal and vertical axes are degrees and minutes of latitude $(\mathrm{N})$ and longitude (E) respectively. Further details as for Fig. 2

Eivissa and Formentera, and small neighbouring islets; B2 comprising Majorca and Cabrera, and small islets; B3 comprising Minorca and small islets; B4 comprising deep waters between Eivissa and Majorca. The areal size of each stratum is given in Table 1.

The distribution of transect lines varied with strata according to previous knowledge on bottlenose dolphin density (University of Barcelona unpubl. data). Density was expected to be comparatively low in Areas A1 and A2, and thus low effort relative to area size was allocated there, in agreement with recommendations on survey design allocation in Buckland et al. (2001). In our case, including more effort in the large areas with lower density would probably not have resulted in many more sightings, but in many more logistic constraints. In contrast, the use of the covariate analysis helped to reduce the heterogeneity arising from differences in detection between geographical strata (see analysis methods). Stratum A1 was surveyed twice and Stratum A2 once (Fig. 2). Given the anticipated higher concentration of dolphins in Cape Creus and the inshore waters of the Balearic Islands, effort allocated was high relative to area size (Table 1). Surveys of Strata A1 and A2 were carried out in October 2001. Cape Creus stratum (C: Fig. 3) was surveyed twice, on 29 January and 12 February 2002. Strata B1, B2 and B3 (Fig. 4) of the Balearic Islands were surveyed twice, in March and September 2002. 

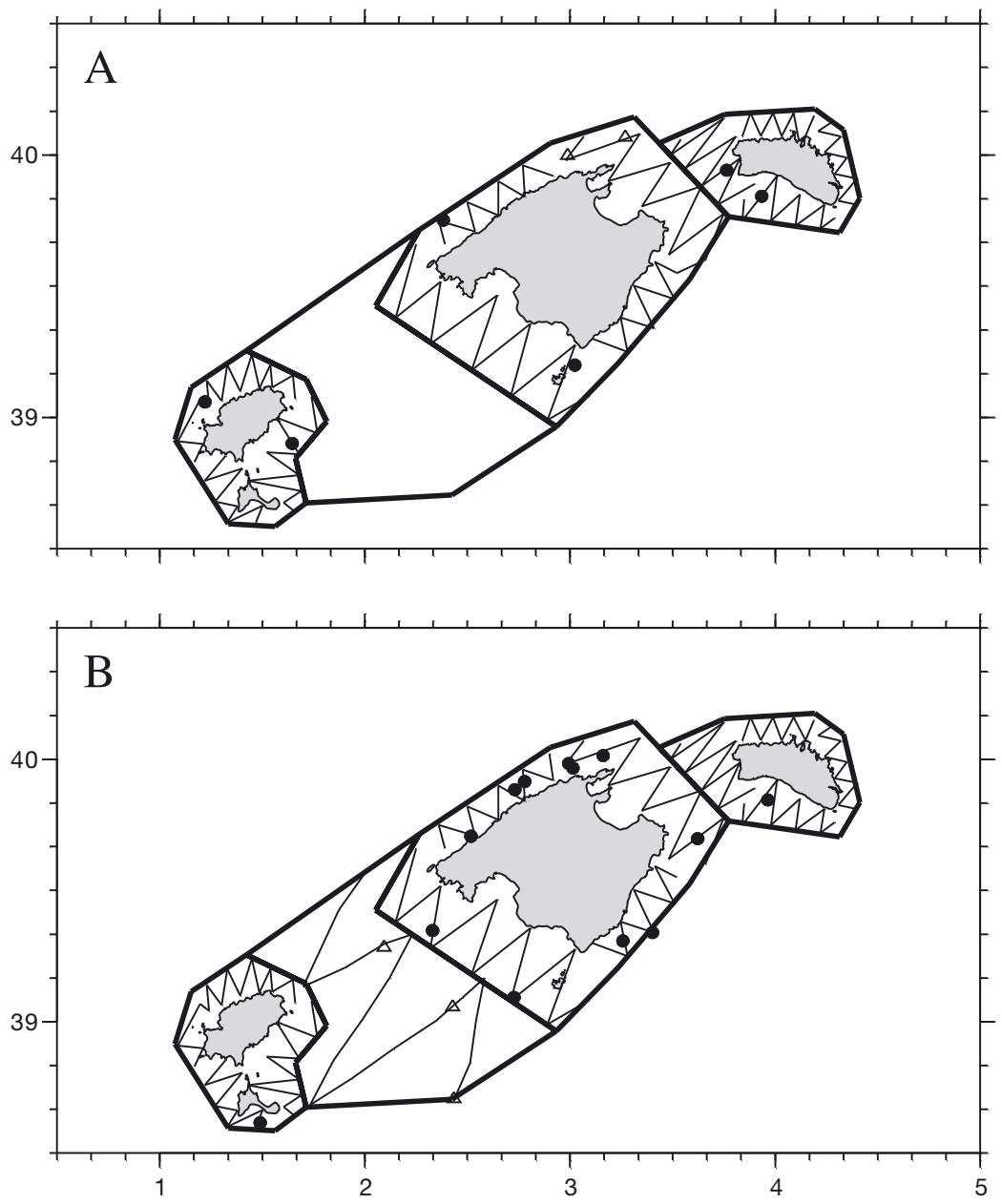

Fig. 4. Balearic Islands, surveyed for abundance of Tursiops truncatus and Stenella coeruleoalba with strata delimited in bold continuous lines. Horizontal and vertical axes are degrees and minutes of latitude (N) and longitude (E) respectively. (A) survey in March 2002; (B) survey in September 2002. Further details as for Fig. 2

Aerial survey procedures. The survey platform was a single-engine high-wing aircraft (Cessna-172). Surveys were flown at $150 \mathrm{~m}$ altitude and an average speed of $150 \mathrm{~km} \mathrm{~h}^{-1}$, and 2 observers (the same throughout the survey) searched for dolphins from the right and left rear windows. The observers had a maximum down-angle from the head position of $75^{\circ}$ below the horizontal. This produced a blind spot beneath the aircraft of $40 \mathrm{~m}$ on each side of the transect line. The measured maximum horizontal scan field was from 40 to $145^{\circ}$, with $0^{\circ}$ being dead ahead and $90^{\circ}$ perpendicular to the transect line. The observers' view was a circular sector defined by this horizontal scan field and a maximum perpendicular distance, $x$ (Fig. 5).

Navigation data (speed, altitude and GPS position) and observation conditions (cloud coverage, and sea state measured by Beaufort scale) were recorded every $10 \mathrm{~min}$. Surveys were limited to optimum sea condi- tions, never exceeding Sea State 3, with a total distribution of effort of $65 \%$ in Beaufort 0 to $1,29 \%$ at Beaufort 2, and $6 \%$ at Beaufort 3. At each sighting of a dolphin group, the time, GPS position and observation conditions were noted, and the perpendicular distance $(x)$ from the transect line to the encountered group was measured. Perpendicular distance was calculated from the aircraft altitude $(H)$ and the angle $(\varphi)$ to each dolphin group as $x=H \tan (90-\varphi) ; \varphi$ was measured with a clinometer (Suunto ${ }^{\circledR}$ PM-5/360PC) when the group was abeam of the aircraft. After noting perpendicular distance, the aircraft circled around the group to confirm species and estimate group size, and then returned immediately to the transect line.

Small-boat procedures. Aerial surveys are affected by visibility bias, caused by undercounting animals missed because they are diving (availability bias), and by factors affecting perception (perception bias), such as cloud cover, sea state or observer fatigue (Laake et al. 1997 and references therein). To address availability bias, data on dive and surface times were collected during boat surveys to study bottlenose dolphin distribution and movements around the Balearic Islands, in June 2003. Surveys were conducted by 3 researchers from a $6.8 \mathrm{~m}$ long inflatable boat with a fibreglass hull (SACS-Ghost) equipped with a Yamaha 4-stroke $115 \mathrm{HP}$ outboard engine. The data collected consisted of surface interval, ventilation frequency, and dive time of different individuals from 12 different groups. According to the definition of detectability of groups (see following

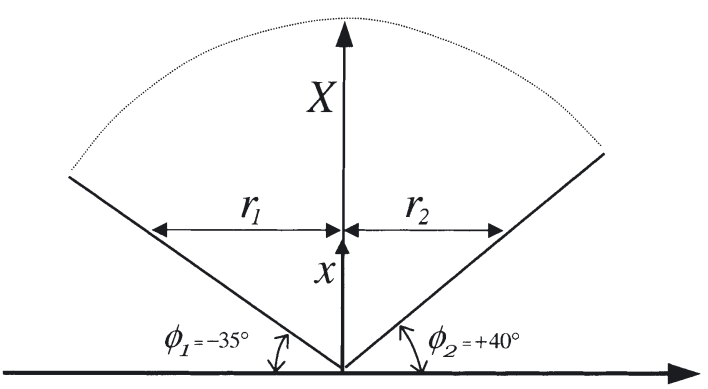

Fig. 5. Effective side view from Cessna-172 aircraft used during surveys. Segment of circle is delimited by angles $\phi_{1}$ and $\phi_{2}$ obstructing lateral view and maximum visibility $X$. Sum of distances $r_{1}$ and $r_{2}$ divided by aircraft speed $(v)$ define $w(x)$, the amount of time that segment of sea surface at perpendicular distance $x$ is in observer's view 


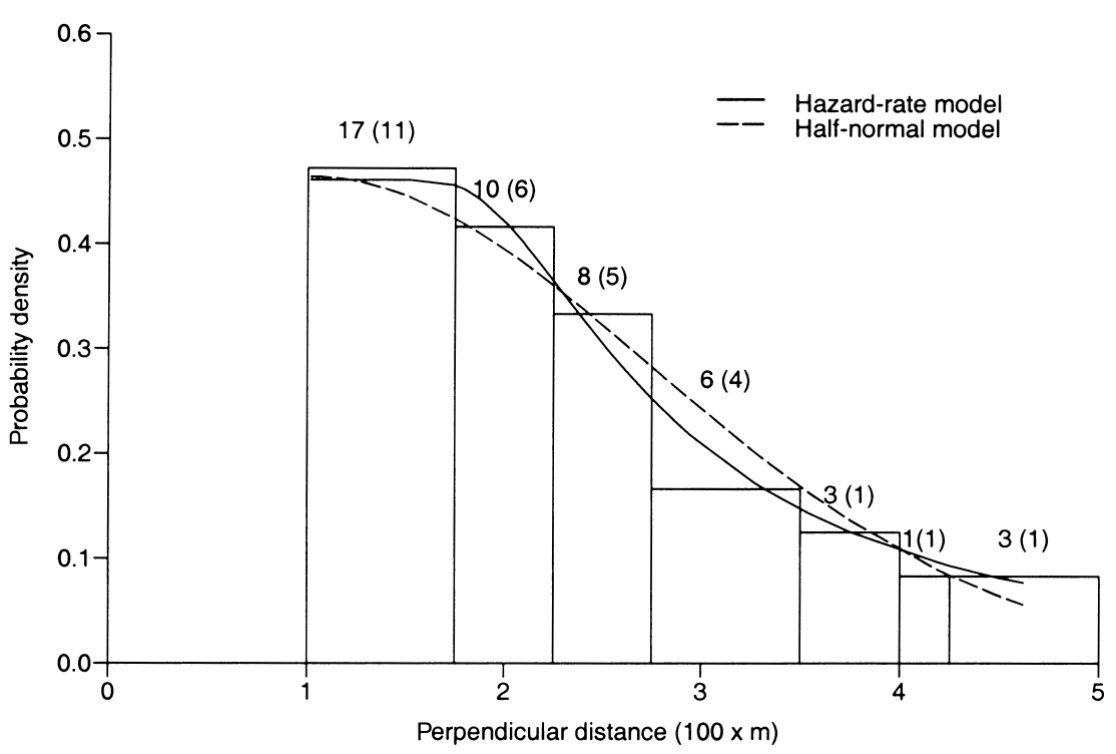

Fig. 6. Tursiops truncatus and Stenella coeruleoalba. Fit of univariate hazard-rate and half-normal models of detection function to histogram of perpendicular distances at which dolphin groups were detected. Distances, in hundreds of meters, were left-truncated at $100 \mathrm{~m}$ and right-truncated at $500 \mathrm{~m}$. Data comprise all bottlenose and striped dolphin group sightings detected during the different surveys. Frequency group counts above histograms correspond to all species together, with counts for bottlenose dolphins in parentheses fect detection of available (non-diving) dolphin groups at a left-truncation distance of $100 \mathrm{~m}$. Under this assumption, heterogeneity due to perception was investigated with multivariate models of the observed detection distances and additional covariates.

Following Laake et al. (1997), at an observed perpendicular distance $x$, dolphin detection was defined by the function $g(x \mid S, Z)$, conditional on the event $S$ that was the occurrence of 1 or more dolphins in a group at or near the surface, and additional perception covariates $Z$ (see below). Dolphin availability, a $(S, x)$, was defined as the probability that a dolphin group at perpendicular distance $X$ was at the surface and within the observer's field of view. From this formulation, it follows that detection probability at perpendicular distance $x$, given a vector of covariates $Z$, is $g(x \mid Z)=g(x \mid S, Z) a(S, x)$. Appendix 1 gives the derivation applied to our aerial surveys and estimations. subsection), a group was detected when 1 or more dolphins in the group were at the surface. Therefore, in agreement with Laake et al. (1997), the length of time the dolphin groups were at or near the surface was measured by combining all intervals with surfacings of 1 or more dolphins less than $30 \mathrm{~s}$ apart as a surface interval, and longer intervals, with all dolphins underwater, as dives. To determine these periods, the groups were closely followed for periods lasting $30 \mathrm{~min}$ to nearly $4 \mathrm{~h}$. Total observation time was $18 \mathrm{~h} 05 \mathrm{~min}$.

Analysis methods. Imperfect (obstructed) vertical visibility invalidated the assumption of perfect detection of non-diving groups on the transect line, i.e. $g(0)=1 ; g(0)$ is the probability of detecting a group on the transect line. To solve this problem, univariate detection-function models were fitted to the perpendicular distances of all dolphin groups detected. A hazard-rate and a half-normal model of the perpendicular distance probability density, $\hat{f}(x)$, showed a considerable shoulder for the frequency counts of small distances after subtracting values below 100 m (Fig. 6). A sensitivity analysis of the estimated density function indicated that this was an appropriate left-truncation distance, and it was thus adopted in further analyses (see Buckland et al. 2001 for details on left-truncation).

The lack of 2 different teams of aerial observers surveying simultaneously but independently precluded any experiment to estimate $\hat{g}(0)$ as affected by perception bias. This led to the additional assumption of per-
Availability was modelled following Laake et al. (1997), with $a(S, x)$ depending on bottlenose dolphin surfacing behaviour and on the amount of time that the region of sea visible from the aircraft window at each perpendicular distance $x$ was in the observer's view, $\hat{w}(x)$. The model described the surfacing and diving behaviour of bottlenose dolphins as a 2-state continuous-time Markov process. A surfacing interval was the length of time that 1 or more dolphins in a group were at or near the surface, and was followed by a diving interval, in which dolphins were below the surface and remained undetectable. The model described a surface-dive interval with the sum of 2 independent exponential random variables, $\lambda$ and $\kappa$, that were the rate parameters of the length of dive and length of surfacing distribution respectively. We used the most general form of Laake et al.'s (1997) model,

$$
\hat{a}(S, x)=\frac{E(s f)}{E(s f)+E(d)}+\frac{\hat{w}(x)-\hat{w}(x)^{2} E(d)^{-1} 0.5}{E(s)+E(d)}
$$

where $E(s f) /[E(s f)+E(d)]$ was evaluated with a ratio estimator of length of time at the surface and total time observed, and $[E(s f)+E(d)]$ was the total time observed divided by the number of monitored surfacediving cycles.

The term $\hat{w}(x)$ was estimated in consideration of the side view from the Cessna-172 used during the survey, which was described by the measured lateral obstruction angles $\phi_{1}$ and $\phi_{2}$. These angles were used to eval- 
uate lateral distances $r_{1}$ and $r_{2}$ at each perpendicular distance $x$ (Fig. 5); e.g. $r_{1}=x \cot (90-\phi)$, where cot is the cotangent. The sum of $r_{1}$ and $r_{2}$ was the window of sea in the observer's view. Considering a constant aircraft speed of $V$,

$$
\hat{W}(x)=\frac{x}{V}\left[\cot \left(90-\phi_{1}\right)+\cot \left(90-\phi_{2}\right)\right]
$$

The abundance of dolphin groups $(\hat{N})$ was estimated with a Horvitz-Thompson-like (Borchers et al. 1998) line-transect estimator (see Appendix 1 for derivation). Abundance of dolphin groups in Stratum $j$ was

$$
\hat{N}_{j}=\frac{A_{j}}{2 L} \frac{\sum_{i=1}^{n} \hat{f}\left(0 \mid Z_{i j}\right)}{\hat{a}(S, 0)}
$$

where $A_{j}$ is the size of the $j$ th stratum, assuming a common availability bias across detected groups and strata. Estimates of $\hat{f}\left(0 \mid Z_{i}\right)$ were obtained with maximum-likelihood optimisation of the density function $f\left(x_{i} \mid Z_{i}\right)$ of the observed data and evaluating at perpendicular distance 0 .

Abundance of bottlenose dolphins in Stratum $j$ was

$$
\hat{N}_{d j}=\frac{A_{j}}{2 L} \frac{\sum_{i=1}^{n} \hat{f}\left(0 \mid Z_{i j}\right) s_{i j}}{\hat{a}(S, 0)}
$$

where $S_{i j}$ is the size of the $i$ th detected group in stratum $j$. The abundance of dolphins in an area comprising several strata was the sum of abundances by strata,

$$
\hat{N}_{d}=\sum_{j=1}^{m} \hat{N}_{d j}
$$

A detection bias-corrected estimate of mean group size by stratum was obtained as

$$
\hat{E}\left(\bar{s}_{j}\right)=\frac{\sum_{i=1}^{n} \hat{f}\left(0 \mid Z_{i j}\right) s_{i j}}{\sum_{i=1}^{n} \hat{f}\left(0 \mid Z_{i j}\right)}
$$

These estimators provided several advantages over the univariate approaches of the detection function: (1) modelling heterogeneity relaxed the assumption of pooling robustness (Buckland et al. 2001), which requires large sample sizes; (2) group size effects on detection, including size-bias, could be directly accounted for by selecting group size as a covariate; (3) given the sparseness of our data, the multivariate approach allowed pooling species and strata to estimate detection without having to assume a common detection function across species and strata.

To model dolphin detection probability, a set of competing models with different covariate effects was initially considered. Covariates were species ( $s p)$, survey stratum (st), cloud cover $(C c)$, sea state (ss), group size $(s)$, and time of day when a sighting occurred $(t d)$. Hazard-rate and half-normal models of perpendicular distances and all possible combinations of up to 2 additional covariates were fitted, and the following statistics were computed: (1) $A I C_{C}$ the small sample Akaike's information criterion (Burnham \& Anderson 2002); (2) $\triangle A I C_{C}$, the difference in $A I C_{C}$ between a fitted model and the lowest $A I C_{C}$ of any model fitted; (3) $A I C_{C} W_{\text {, the }} A I C_{C}$ weight. From the initial set of $M$ competing models, the $A I C_{C}$ weight for model $M_{i}$ was

with

$$
A I C_{C} W_{i}=\frac{\exp \left(-0.5 \Delta A I C_{C} \mid M_{i}\right)}{\sum_{i=1}^{M} \exp \left(-0.5 A I C_{C_{i}}\right)}
$$

$$
A I C_{C}=-2 \log [\mathcal{L}(\theta ; X, Z)]+2 k+\frac{k(k+1)}{n-k-1}
$$

where $\log \left[\mathcal{L}\left(\theta_{;}, Z\right)\right]$ was the model log-likelihood, $k$ was the number of parameters and $n$ was sample size (Burnham \& Anderson 2002).

The relative importance of different covariates was investigated using $A I C_{C}$ weights, $A I C_{C} W$. We obtained the sums of the $A I C_{C} W$ of all models in which a unique covariate appeared; the larger the sum across models for one covariate, the more important its explanatory power was relative to others (see Table 2). Selecting the most influential covariates in this way, multimodel inference was based on a confidence set, which consisted of models including these covariates with an $\triangle A I C_{C}$ value smaller than 4 . Values of 4 or above corresponded to models with very low or no empirical support, and were discarded for inference. With the confidence set, an averaged estimate was obtained as

$$
\hat{\bar{f}}(0 \mid Z)=\sum_{i} A I C_{C} w_{i} \hat{f}(0 \mid Z)_{i}
$$

and was used in the abundance estimators.

Empirical variances of abundance and group size could be readily obtained using a delta method (Seber 1982) derivation for the variance of $\hat{p}$, the probability to detect a dolphin group (Appendix 1), as

$$
\operatorname{vâr}\left(\sum p_{i}^{-1}\right)=W^{2} \sum \hat{f}\left(0 \mid Z_{i}\right)^{2}-W \sum \hat{f}\left(0 \mid Z_{i}\right)
$$

and further derivation for the variance of $\hat{N}$. However, more robust estimates of variability and $95 \%$ confidence limits were obtained with nonparametric bootstrapping.

In each of 4999 bootstrap replicates, transects within strata with their corresponding detected dolphin groups were resampled with replacement. The confidence set of models was fitted at each replicate to estimate $\hat{f}\left(0 \mid Z_{i}\right)$, and was combined with the other components of the abundance estimators to obtain a bootstrap abundance for each stratum. Because $\hat{a}(S, 0)$ was estimated independently of the aerial surveys, its variability was accounted for by selecting in each replicate 
a sample with replacement of all dolphin groups monitored during the boat surveys and re-estimating $\hat{a}(S, 0)$. Balanced bootstrapping (Davison \& Hinkley 1997) by strata and survey was adopted to ensure that all transects were selected with the same frequency. The $95 \%$ confidence limits were obtained from the bootstrap distribution using the percentile method, allowing for model selection uncertainty by selecting the best models to estimate $\hat{\hat{f}}\left(0 \mid Z_{i}\right)$ at each bootstrap.

Specific code in S (Venables \& Ripley 2000) was written to implement the analysis above described. The S code included calls to FORTRAN routines for the maximum likelihood optimisation of the covariate density models. These routines consisted of modifications of Buckland's (1992) algorithm to fit maximumlikelihoods of density functions using the NewtonRaphson method.

\section{RESULTS}

\section{Survey coverage and dolphin detectability}

The distribution of search effort was in good agreement with the survey design, ensuring maximum coverage of all the strata in each survey. Search effort was only reduced in the NE extreme of Stratum A2 (Fig. 2) because of logistic constraints, but the lack of coverage was minimum in that area. Most of the effort in all strata was in optimum sea-state conditions (Beaufort 0 to 2 ), except $6 \%$, which was in moderately good sea- state conditions (Beaufort 3). This ensured a maximum homogeneity in sea state over space and time, making the detectability process more similar between surveys.

Among covariates affecting detectability, time and cloud cover had the higher explanatory power (Table 2). Time was positively related to detection distance, with more groups being detected at larger perpendicular distances towards evening. This relationship reflected the combination of an increase in dolphin surface activity and the improvement of sighting conditions, with a lower horizontal position of the sun towards evening. The effect of cloud cover was related to changes in the reflection of sunlight on the sea surface; with increased cloud cover, dolphin groups were detected at shorter perpendicular distances. Other covariates had marginal effects with very low explanatory power. In particular, the effect of size-bias, a bias caused by detecting more large groups at larger perpendicular distances than small groups, was negligible. Finally, the detection of bottlenose dolphins was not dissimilar to that of striped dolphins Stenella coeruleoalba, and dolphin detectability in general appeared not to be affected by strata or survey, although the sample size in most strata was probably too small to detect differences.

The selection of covariates was similar using the hazard-rate and half-normal models, and both models were included in the confidence set used for inference. Using the confidence set (Table 3: first 5 models), the estimated mean $\hat{f}(0 \mid Z)$ varied from 2.990 to 3.374 , indi-

Table 2. Comparison of $A I C_{C} W_{i}$ (Akaike weights; see subsection 'Analysis methods' for details) of multivariate detection function models with all possible combinations of detection perpendicular distances and 1 or 2 additional covariates. Each column corresponds to models that contain a unique covariate, and sums indicate comparative explanatory power of each covariate compared the others. All combinations of covariates were evaluated with half-normal and hazard-rate models. sp: species; st: stratum; CC: cloud cover; $s S$ : sea state; $s$ : group size; $t d$ : time of day. Combinations of covariates are given in parentheses

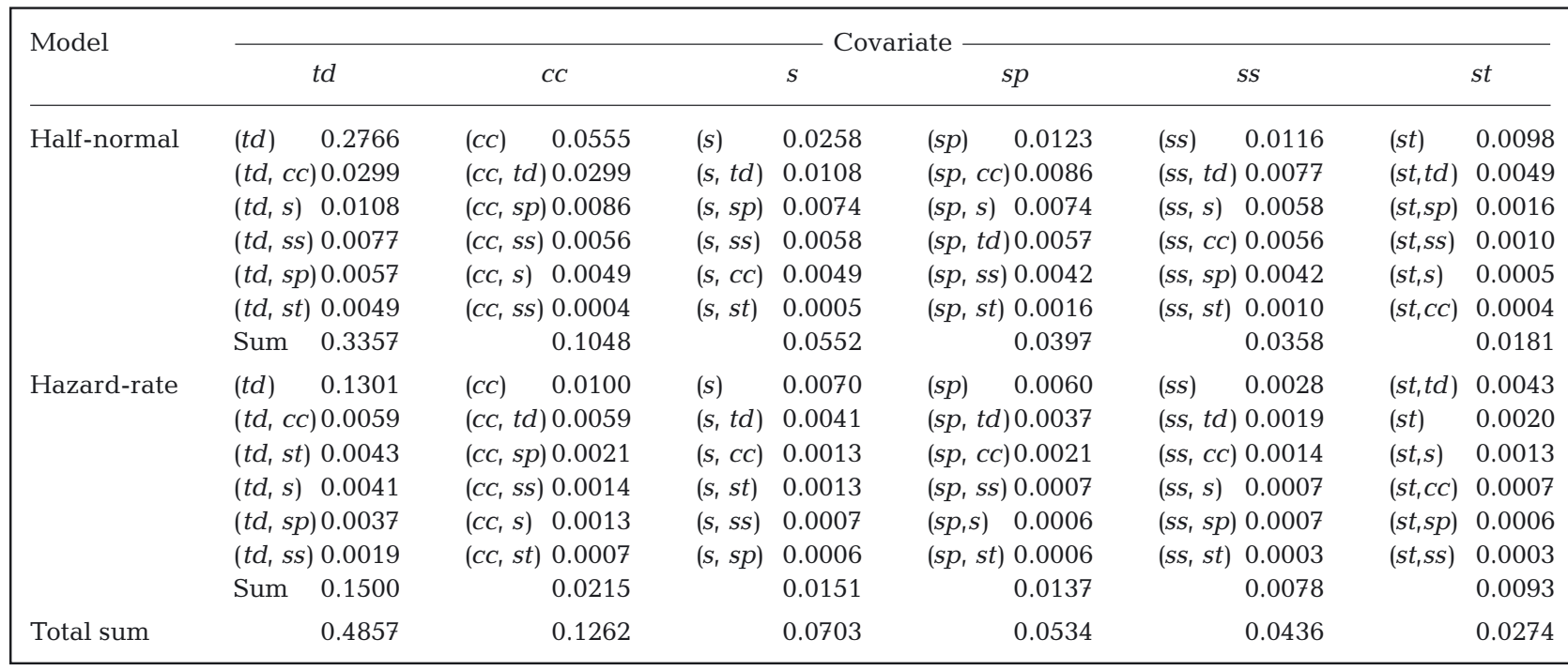


Table 3. Summary of detection-function model fits with $A I C_{C}$ $\triangle A I C_{C}$ and $A I C_{C} W$ (see subsection 'Analysis methods' for Akaike statistic definitions), and estimated mean $\hat{\bar{f}}\left(0 \mid Z_{i}\right)$. For brevity, only models with $A I C_{C} W$ above 0.005 are shown, although all possible models with combinations of perpendicular distances and up to 2 additional covariates were considered (Table 2). Each possible combination of covariates was fitted with the half-normal and hazard-rate models. Multimodel inference was based on a confidence set consisting of models with $\Delta A I C_{C}$ values <4. sp: species; st: stratum; $C$ : cloud cove; ss: sea state; $s$ : group size; $t d$ : time of day; $x$ : perpendicular distance

\begin{tabular}{|c|c|c|c|c|}
\hline Model & $A I C_{C}$ & $\Delta A I C_{C}$ & $A I C_{c} W$ & $\hat{\bar{f}}\left(0 \mid Z_{i}\right)$ \\
\hline Half-normal $(x, t d)$ & 116.7387 & 0 & .2766 & 3.3743 \\
\hline Half-normal $(x)$ & 116.9686 & 0.2299 & 2466 & 1712 \\
\hline Hazard-rate $(x, t d)$ & 118.2482 & 5094 & 1301 & 3739 \\
\hline Hazard-rate $(x)$ & 119.3 & .6004 & 4 & 1572 \\
\hline Half-normal & 119. & 3.2140 & 5 & 9902 \\
\hline Half- & 121.1 & 4.4 & 9 & .2717 \\
\hline Half-I & 121. & 4.7 & 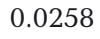 & 353 \\
\hline Half-r & $122 . c$ & 6.2258 & 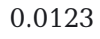 & 3.0012 \\
\hline $1(x, s s)$ & 123.0 & 6.3489 & 0.0 & 2.8176 \\
\hline$l(x, t d, s)$ & 123 & 6.48 & 0.0 & 3.2682 \\
\hline$(x, C C)$ & 123 & 53 & 10 & 2.4701 \\
\hline Half & 123 & 71 & & .0014 \\
\hline Half-normal $(X, C C, S)$ & 123. & & & 3.2199 \\
\hline Half-normal $(x, t d, s s)$ & 123.9 & 7.1650 & & 3.0313 \\
\hline Half-normal $(x, s, s p)$ & 123. & 7.2340 & & 2.9585 \\
\hline Hazard-rate $(x, s)$ & 124.0 & 7.3413 & & 3.1476 \\
\hline Hazard-rate $(x, s p)$ & 124.4174 & 7.6787 & 0.0060 & 2.7499 \\
\hline Hazard-rate $(x, t d, c c)$ & 124.4275 & 7.6888 & 0.0059 & 2.9580 \\
\hline Half-normal $(X, S, S S)$ & 124.4613 & 7.7226 & 0.0058 & 2.8531 \\
\hline Half-normal $(x, t d, s p)$ & 124.5138 & 7.7751 & 0.0057 & 3.2196 \\
\hline Half-normal $(X, C C, S S)$ & 124.5432 & 7.8044 & 0.0056 & 2.9935 \\
\hline
\end{tabular}

cating variability due to covariate effects, and especially due to time. The mean unconditional $\hat{\hat{f}}(0 \mid Z)$ for bottlenose dolphins was estimated as $3.877(\mathrm{CV}=0.19$; $95 \% \mathrm{CI}=2.333-5.219$ ), which corresponded to an effective strip half-width of $260 \mathrm{~m}$. The mean conditional (using only the best model) $\hat{f}(0 \mid Z)$ was estimated as $3.386(\mathrm{CV}=0.08 ; 95 \% \mathrm{CI}=2.704-3.787)$, and was not very different from the unconditional estimate. In contrast, high differences in variability indicated a large uncertainty due to model selection, mostly driven by covariate effects but also by the selection of competing parametric models.

The mean proportion of time spent by any bottlenose dolphin group at the surface $E(s f) /[E(s f)+E(d)]$ (Eq. 1) was estimated as $0.77(\mathrm{SE}=0.10)$. The average surface interval was $231.3 \mathrm{~s}(\mathrm{SE}=29.4)$, and the average dive interval was $68.7 \mathrm{~s}(\mathrm{SE}=8.7)$. The availability bias at perfect detection distance $\hat{a}(S, 0)$ was estimated as $0.7784(\mathrm{CV}=0.04 ; 95 \% \mathrm{CI}=0.721-0.825)$, and comprised a very small component of the variability in the abundance estimate. This estimate indicated that, on average, more than $22 \%$ of the bottlenose dolphin groups were diving and remained undetected while the aircraft flew over.

\section{Distribution of detected dolphin groups and group-size estimates}

Bottlenose and striped dolphins were the most commonly encountered species and were present throughout the surveyed area. Neither of the 2 species was abundant, and their distributions overlapped in offshore waters (Fig. 2).

The surveys of Cape Creus (Stratum C) only resulted in 3 sightings of bottlenose dolphin groups and an additional sighting of unidentified delphinids, which were likely to be bottlenose dolphins (Fig. 3).

The surveys in the inshore waters of the Balearic Islands (Strata B1, B2 and B3) produced very different results in the various seasons. In March 2002, the number of confirmed sightings was only 6 , i.e. half the number in September 2002, when 13 were sighted. The homogeneity in sighting conditions and the fact that the same observers and platforms were used in both surveys suggested seasonal sighting patterns. The differences in sighting numbers between seasons could reflect animal movement around the Balearic Islands, and a likely inshore-offshore movement pattern. Finally, the absence of bottlenose dolphin sightings for Stratum B4 confirmed its low density in deep offshore waters where striped dolphins, an offshore species in the Mediterranean (Forcada et al. 1994, Aguilar 2000), were more likely to occur (Fig. 4B).

Bottlenose dolphins were detected mostly in groups of 1 to 10 individuals, and all groups were smaller than 15, except for 1 group of 29 dolphins. Mean group size was 7 , and the lack of detectability bias made the mean very similar to the bias-corrected mean group size, estimated as $6.90(\mathrm{CV}=0.15$; $95 \% \mathrm{CI}=5.11-9.37$ ) for offshore waters of the Balearic Sea (Stratum A2), and $6.36(\mathrm{CV}=0.20 ; 95 \% \mathrm{CI}=$ 4.14 - 9.11) for the inshore Balearic Islands (Strata B1, B2 and B3). In contrast, group sizes of striped dolphins ranged from 1 to 60 , with most groups comprising 5 to 20 dolphins, a mean of 16.11 , and a bias-corrected mean group size estimate of $16.32(\mathrm{CV}=0.23$; $95 \%$ CI $=9.98-24.99$ ) for Strata A.

\section{Abundance estimates}

Bottlenose dolphin abundance estimates were based on confirmed sightings, which were scarce in all surveys and strata, regardless of their areal size. Point estimates, coefficients of variation and $95 \%$ confidence limits are summarised in Table 4 . On the Catalan coast (Stratum A1) and in the offshore Balearic Sea (Stratum A2) mean density was $0.88(0.19-1.82)$ bottlenose dol- 
Table 4. Tursiops truncatus. Abundance estimates of bottlenose dolphins by area. Coefficients of variation (CV) and $95 \%$ confidence intervals (CI) obtained from the unconditional estimates of $\hat{\hat{f}}(0 \mid Z)$ computed in 4999 bootstrap replicates (see subsection 'Analysis methods' for details). Areas corresponding to stratum combinations are labelled as in Fig. 1. Estimates for inshore Balearic Islands are for spring, autumn and averaged across seasons. n: number of sightings of bottlenose dolphins only, although sightings of other species were used to estimate $\hat{\bar{f}}\left(0 \mid Z_{i}\right) ; \hat{N}_{d}$ abundance of dolphins

\begin{tabular}{|llrrrrr|}
\hline Area & Stratum & $\mathrm{n}$ & $\hat{N}_{d}$ & $\mathrm{CV}$ & \multicolumn{2}{c|}{$\begin{array}{c}\text { 95\% CI } \\
\text { Low limit High limit }\end{array}$} \\
\hline Catalan coast & A1 & 6 & 871 & 0.56 & 48 & 1910 \\
Offshore Balearic Sea & A2 & 6 & 6783 & 0.52 & 841 & 14817 \\
Balearic Sea & A1+2 & 12 & 7654 & 0.47 & 1608 & 15766 \\
Inshore Balearic Islands & B1, 2+3 & & & & & \\
& Spring & 6 & 727 & 0.47 & 149 & 1481 \\
& Autumn & 13 & 1333 & 0.44 & 419 & 2617 \\
& Mean & 19 & 1030 & 0.35 & 415 & 1849 \\
\hline
\end{tabular}

phins every $10 \mathrm{~km}^{2}$. For the Balearic Islands (B1, B2, B3), density was $0.60(0.12-1.23)$ individuals in spring, and $1.10(0.35-2.17)$ in autumn, and mean density was 0.85 (0.34 - 1.53). The abundance of bottlenose dolphins in the whole the area surveyed, including the inshore waters of the Balearic Islands, was estimated as $7654(\mathrm{CV}=0.47 ; 95 \% \mathrm{CI}=1608-15766)$. Their abundance in inshore waters of the Balearic Islands varied from 727 (CV $=0.47 ; 95 \% \mathrm{CI}=149-1481)$ dolphins in spring 2002 to $1333(\mathrm{CV}=0.44 ; 95 \% \mathrm{CI}=$ 419 - 2617) dolphins in autumn 2002.

\section{DISCUSSION}

\section{Methodological considerations}

The use of an aircraft was essential for efficiently surveying the study area in the shortest possible time. This avoided repeat sightings of the same individuals, which could move between small strata during the survey. The aircraft had limitations in vertical detection, but left-truncation was an effective method of dealing with the problem of obstructed view, given the large shoulder in the detection function. However, many sightings were likely to have been missed along the transect line, reducing the encounter rate and sample size, and future surveys would greatly benefit from an unobstructed view.

Aerial surveys of cetaceans in other regions have used visibility (combining availability and perception) correction factors for delphinids, including bottlenose dolphins. Aerial surveys specific for bottlenose dolphins in tandem aircraft (Carretta et al. 1998) estimated a range of visibility bias of 0.446 to 0.735 for groups of between 1 and 10 bottlenose dolphins, and between 0.781 and 0.990 for larger groups. For these ranges, the best estimates were considered to be 0.735 for small groups and 0.990 for large groups. For small groups, like the majority of groups encountered in our surveys, the availability estimates of Caretta et al. (1998) were in very good agreement with those found by us ( 0.735 versus 0.778$)$, assuming that the component due to perception bias was small, i.e. 0.95 to 0.99 . If this was the case, as we assume it was, the bias due to perception in our estimates was likely to be very small.

These results highlight the relevance of estimating availability bias in aerial sighting surveys of bottlenose dolphins. However, because availability is an inverse multiplier in the line-transect abundance estimator, resulting abundance estimates are sensitive to this quantity and future analyses will benefit from further testing. An ideal test would be the use of alternative approaches such as surveys with aircraft flying in tandem (Carretta et al. 1998, Hiby \& Lovell 1998), although these methods require large sample sizes for estimation, which would be difficult to obtain in sparse populations such as that in the present study. An alternative could be the use of combined aerial and land-based experiments (Laake et al. 1997), if such experiments are feasible in the study areas.

The covariate analysis provided substantial improvement by its ability to reduce the heterogeneity associated with the detection process. It helped to avoid the assumption of a common detection function across species and other factors, which is sometimes required in studies with reduced sample sizes. Other studies often consider post-stratification (Buckland et al. 2001), but are limited by the minimum sample-size requirements to fit independent detection-function models to data for different stratification levels. An additional advantage of covariate analysis is the possibility of model selection and multimodel inference of covariate effects, which in our case enabled a robust estimation approach. Unconditional abundance estimates better reflected the uncertainty arising from the modelling and the covariate selection processes, and model selection uncertainty was taken into account in the estimates of precision. Uncertainty is high when there are many competing models of very different structure but good empirical support. Competing models can equally contribute to inference and, as seen in this study, multimodel inference avoids overestimates of precision, which may be misleading in future comparisons or in risk-assessment studies. 
The use of a covariate analysis also has limitations that must be considered. Among them are the sample size requirements of covariate effects when these are defined as multiple levels of a factor. Each level is an additional parameter to fit in the model optimisation and requires more data than a continuous covariate, which is described by just 1 parameter. In this regard, covariate models will benefit from further research in optimisation facilities, but also from larger sample sizes, if at all possible. Another limitation is imposed by the experimental design and the collection of relevant covariates. A preliminary assessment of covariate effects is a good way to avoid spurious effects, which may be unwanted for inference. Such an assessment may be useful in selecting the most appropriate covariates to measure during future surveys.

\section{Bottlenose dolphin abundance estimates}

This analysis has produced the first absolute abundance estimate of bottlenose dolphins in NW Mediterranean waters, and constitutes a baseline upon which to assess future changes in their abundance around the Balearic Islands. The surveys suggested seasonal changes in abundance in coastal waters of the Balearic Islands, but the seasonal abundance estimates were not significantly different. While the number of sightings was low, the high allocation of effort and consistency in observers and good sighting conditions made both surveys highly comparable. Thus, between-survey differences in abundance were likely to be real, and not just extremes within the mean range of variability. Because the analysis of the detection function ruled out differences in detection probability between surveys, seasonality was the most likely explanation for such differences. Thus, seasonal fluctuations should be further investigated and not initially discarded in future studies.

Previous line-transect surveys of the western Mediterranean (Forcada et al. 1994, 1995, Forcada \& Hammond 1998) rarely found bottlenose dolphins in pelagic waters. Most groups occurred in coastal areas of the main insular systems, the Balearic Islands, Corsica, Sardinia, and around small islands near the continent. As in the present surveys, the encounter rate of bottlenose dolphin groups was then very low, but survey effort was allocated to provide results at a larger scale and aimed at detecting striped dolphin groups in a basin-wide survey. Although the results between surveys are thus difficult to compare, the overall low density of bottlenose dolphins was a common characteristic.

\section{Conservation and management implications}

Despite the obvious advantages of the use of covariate analysis, dolphin groups were rare and the surveys provided imprecise abundance estimates. This lack of precision may hamper the detection of population trends in surveys conducted across time. The number and frequency of future surveys required to detect population trends in the future could be evaluated with a power analysis (e.g. Wilson et al. 1999, Forcada 2000). However, the limitations imposed by small sample sizes will remain, regardless of the method. Thus, a precautionary approach for conservation management (e.g. Taylor \& Gerrodette 1993) would be most appropriate until the categorisation of risk can be supported by data on fluctuations, habitat fragmentation and geographic range.

Surveys on fishing interactions suggest that in the Balearic Islands about 30 dolphins are killed every year, either by incidental entanglements in fishing nets or by deliberate kills to avoid damage to gear or competition for fishing resources (Silvani et al. 1992). When related to the inshore subpopulation, here estimated at 727 to 1333 individuals, these figures may exceed the usual safety limits of acceptable removals, which for dolphin populations are commonly set at about 1\% (International Whaling Commission 1995). However, conflict with fisheries is not the only threat to the conservation of these species. In 1990-1991, the sympatric population of striped dolphins suffered a morbillivirus epizootic (Aguilar \& Raga 1993) that was claimed to have been triggered by immunosuppressive effects of high levels of organochlorine pollutants, particularly polychlorinated biphenyls, present in their tissues (Kannan et al. 1993, Aguilar \& Borrell 1994). Organochlorine levels in the western Mediterranean bottlenose dolphins are as high as those in striped dolphins (Corsolini et al. 1995), and probably above threshold levels associated with adverse effects; therefore potential adverse xenobiotic impacts on populations cannot be ruled out. Moreover, in the NW Mediterranean, bottlenose dolphins base their diet on prey such as hake Merluccius merluccius, conger Conger conger and octopus Octopus vulgaris (Blanco et al. 2001) that are commercially exploited or overexploited. Fishing is intense throughout the region, and in the last few decades the abundance of several main target species have been severely reduced (Caddy \& Griffiths 1990, Caddy 1997). The availability of critical diet elements is therefore likely to have decreased at a comparable rate. Whatever the role of the different human-related pressures on bottlenose dolphin populations, its significance is unclear. The species has clearly suffered a sharp decline in the last decades (Aguilar et al. 1997). Monitoring and periodic assess- 
ment of population abundance, taking the present estimates as a baseline, are critical in order to ensure conservation and design management strategies.

Genetic studies have shown that the western Mediterranean population of bottlenose dolphins probably originated from the offshore eastern Atlantic Ocean ecotype, but later adopted mostly coastal habits (Natoli \& Hoelzel 2000). Previously reported offshore movements of bottlenose dolphins in the western Mediterranean were attributed to stragglers originating from coastal areas (e.g. Dhermain et al. 1999). Our results indicate that, although many individuals occupy inshore waters, a significant part of the population still occurs in open waters. This indicates that the subpopulation concept, traditionally based on subjectively perceived limits of geographic range, should be reconsidered. The hypothesis of a Balearic Island subpopulation within the western Mediterranean does not necessarily hold, and needs to be examined in the light of population studies on genetics, morphometrics, chemical indicators and/or other parameters.

Their low absolute density in open waters of the Balearic Sea and relatively high mean abundance around the Balearic Islands suggest that the inshore waters of the islands provide a critical habitat for the dolphins. The possible seasonality of bottlenose dolphins using these habitats needs to be investigated in relation to increased noise pollution, boat traffic, and overall habitat encroachment during the summer period caused by tourism. The Balearic Islands receive about 250000 foreign visitors every year, almost $70 \%$ of them during summer. Leisure boats are estimated to be about 35000 during the summer, i.e. 1 boat $25 \mathrm{~m}^{-1}$ coastline. In winter, almost all the boats are inactive, in dry dock or in sheltered in harbours (GOB 2002; available at: http://www.gobmallorca.com/mar/index.htm). While collisions of bottlenose dolphins with boats seem to be the exception, the potentially adverse effect of vessel intrusion and noise on this species has been suggested by many reports in other geographical areas (see Dolman et al. 2001 for review) and should not be disregarded. Several surveys have found that during periods of intense boat traffic dolphins show altered sound-emission and swimming behaviour (Evans et al. 1992, Scarpaci et al. 2000, Nowacek et al. 2001), or are forced to abandon primary foraging habitats (Allen \& Read 2000). Hence, the impact of tourism needs to be considered in an ecosystem-management context. Simultaneous with the elimination or mitigation of adverse fishing interactions, the protection of inshore waters and the regulation of tourism in key areas should be considered a high priority for conservation.

Acknowledgements. Thanks are due to J. Pantoja (Directorate for Nature Conservation of Spain), T. Raga (University of
Valencia), and J. Ruiz (Departament de Medi Ambient, Generalitat de Catalunya) for their assistance in the planning and execution of the air surveys. Thanks are extended to the pilots and personnel of Airpal, the Son Bonet Aeroclub, Marratxí, and the 'Cos d'Agents Rurals'. The flights off Catalonia were carried out with aircraft made available by the Departament de Medi Ambient of the Generalitat de Catalunya. This work was mainly funded by the General Directorate for Nature Conservation of Spain's Ministry of the Environment, and by the Life financial instrument of the European Community. The Fundació pel Desenvolupament Sostenible (FDS) also contributed assistance and partial funding for the boat fieldwork. Psion Teklogix provided a Netpad ${ }^{\circledR}$ handheld computer used on the boat surveys. J. Laake provided a preliminary review of the statistical analysis methods, and 5 anonymous reviewers provided useful comments for improving the manuscript.

\section{LITERATURE CITED}

Aguilar A (2000) Population biology, conservation threats, and status of Mediterranean striped dolphins (Stenella coeruleoalba). J Cetacean Res Manag 2:17-26

Aguilar A, Borrell A (1994) Abnormally high polychlorinated biphenyl levels in striped dolphins (Stenella coeruleoalba) affected by the 1990-1992 Mediterranean epizootic. Sci Total Environ 154:237-247

Aguilar A, Raga JA (1993) The striped dolphin epizootic in the Mediterranean Sea. Ambio 22:524-528

Aguilar A, Forcada J, Arderiu A, Borrell A, Monnà A, Aramburu MJ, Pastor T, Cantos G (1997) Inventario de los cetáceos de las aguas atlánticas peninsulares. Instituto Nacional para la Conservación de la Naturaleza, Ministerio de Agricultura, Pesca y Alimentación, Report 1:1-182. Directorate for Nature Conservation, Spanish Ministry of the Environment, Madrid, Spain

Allen M C, Read A J (2000) Habitat selection for foraging bottlenose dolphins in relation to boat density near Clearwater, Florida. Mar Mamm Sci 16:815-824

Blanco JC, González JL (1992) Libro rojo de los vertebrados de España. Ministerio de Agricultura, Pesca y AlimentaciónICONA, Colección Técnica, Madrid

Blanco C, Salomón O, Raga JA (2001) Diet of the bottlenose dolphin (Tursiops truncatus) in the western Mediterranean Sea. J Mar Biol Assoc UK 81:1053-1058

Borchers DL, Buckland ST, Goedhart PW, Clarke ED, Hedley S L (1998) Horvitz-Thompson estimators for doubleplatform line transect surveys. Biometrics 54:1221-1237

Borchers DL, Buckland ST, Zucchini W (2002) Estimating animal abundance: closed populations. Springer-Verlag London, Goldalming, UK

Buckland ST (1992) Maximum likelihood fitting of hermite and simple polynomial densities. Appl Stat 41:241-266

Buckland ST, Anderson DR, Burnham KP, Laake JL, Borchers DL, Thomas L (2001) Introduction to distance sampling: estimating abundance of biological populations. Oxford University Press, New York

Burnham KP, Anderson DR (2002) Model selection and multimodel inference: a practical information-theoretic approach, 2nd edn. Springer-Verlag, New York

Caddy JF (1997) Review of the state of world fishery resources: marine fisheries. B. Regional reviews 5: Mediterranean and Black Sea. FAO Fish Circ 920

Caddy JF, Griffiths RC (1990) Recent trends in the fisheries and environment in the General Fisheries Council for the Mediterranean (GFCM) area. Stud Rev Gen Fish Counc Mediterr (FAO) 63:1-71 
Carretta JV, Forney KA, Laake JL (1998) Abundance of southern California coastal bottlenose dolphins estimated from tandem aerial surveys. Mar Mamm Sci 14:655-675

Corsolini S, Focardi S, Kannan K, Tanabe S, Borrell A, Tatsukawa R (1995) Congener profile and toxicity assessment of polychlorinated biphenyls in dolphins, sharks and tuna collected from Italian coastal waters. Mar Environ Res 40: $33-53$

Davison AC, Hinkley DV (1997) Bootstrap methods and their application. Cambridge University Press, Cambridge

Dhermain F, Ripoll T, Bompar JM, David L, Di Méglio N (1999). First evidence of the movement of a bottle-nosed dolphin Tursiops truncates, between Corsica and Hyeres archipelago, south-eastern France. Europ Res Cetaceans 13:306

Dolman SJ, Parsons ECM, Simmonds MP (2001) Noise sources in the cetacean environment. International Whaling Commission doc SC/54/E7. International Whaling Commission, Impington, Cambridge

Evans PGH, Canwell PJ, Lewis E (1992) An experimental study of the effects of pleasure craft noise upon bottlenosed dolphins in Cardigan Bay, West Wales. Europ Res Cetaceans 6:43-46

Forcada J (2000) Can population surveys show if the Mediterranean monk seal colony at Cap Blanc is declining in abundance? J Appl Ecol 37:171-181

Forcada J (2002) Multivariate methods for size-dependent detection in conventional line transect sampling. Administrative Report LJ-02-02, National Marine Fisheries Service, Southwest Fisheries Science Center, La Jolla, CA

Forcada J, Hammond PS (1998) Geographical variation in abundance of striped and common dolphins of the western Mediterranean. J Sea Res 39:313-325

Forcada J, Aguilar A, Hammond PS, Pastor X, Aguilar R (1994) Distribution and numbers of striped dolphins in the western Mediterranean Sea after the 1990 epizootic outbreak. Mar Mamm Sci 10:137-150

Forcada J, Notarbartolo di Sciara G, Fabbri F (1995) Abundance of fin whales and striped dolphins summering in the Corso-Ligurian Basin. Mammalia 59:127-140

Fortuna CM, Wilson B, Wiemann A, Matesic M, Oehen S, Pribanic S, Riva L (2000) How many dolphins are we studying and is our study area big enough? Europ Res Cetaceans 14:370-373

Hansen LJ, Defran RH (1990) A comparison of photo-identification studies of California coastal bottlenose dolphins. Rep Int Whal Comm Spec Issue 12:101-104

Hayes RJ, Buckland ST (1983) Radial-distance models for the line-transect method. Biometrics 39:29-42

Hiby L, Lovell P (1998) Using aircraft in tandem formation to estimate abundance of harbour porpoise. Biometrics 54: $1280-1289$

International Whaling Commission (1995) Report of the subcommittee on management procedures. Rep Int Whal Comm 45:104-119

IUCN (International Union for Conservation of Nature and Natural Resources) (2001) Red list categories. IUCN, Gland, Switzerland

Kannan K, Tanabe S, Borrell A, Aguilar A, Focardi S, Tat- sukawa R (1993) Isomer-specific analysis and toxic evaluation of polychlorinated biphenyls in striped dolphins affected by an epizootic in the western Mediterranean Sea. Arch Environ Contam Toxicol 25:227-233

Laake J L, Calambokidis J, Osmek S D, Rugh D J (1997) Probability of detecting harbor porpoise from aerial surveys: estimating $g(0)$. J Wildl Manag 61:63-75

Marques FFC (2001) Estimating wildlife distribution and abundance from line transect surveys conducted from platforms of opportunity. $\mathrm{PhD}$ thesis, University of St. Andrews, St. Andrews, Scotland

Natoli A, Hoelzel A R (2000) Genetic diversity in a Mediterranean population of the bottlenose dolphin in a context of world-wide phylogeography. Europ Res Cetaceans 14:343

Notarbartolo di Sciara G, Aguilar A, Bearzi G, Birkun A, Frantzis A (2002) Overview of known or presumed impacts on the different species of cetaceans in the Mediterranean and Black Seas. In: Notarbartolo di Sciara G (ed) Cetaceans of the Mediterranean and Black Seas. ACCOBAMS, Monaco, p 194-196

Nowacek SM, Wells RS, Solow AR (2001) Short-term effects of boat traffic on bottlenose dolphins, Tursiops truncatus, in Sarasota Bay, Florida. Mar Mamm Sci 17:673-688

Quinn TJ, Gallucci VF (1980) Parametric models for line transect estimators of abundance. Ecology 61:292-302

Ramsey FL, Wildman V, Engbring J (1987) Covariate adjustments to effective area in variable-area wildlife surveys. Biometrics 43:1-11

Reeves RR, Smith BD, Crespo EA, Notarbartolo di Sciara G (2003) Dolphins, whales and porpoises: 2002-2010 conservation action plan for the world's cetaceans. IUCN, Gland, Switzerland

Seber GAF (1982) The estimation of animal abundance. 2nd edn. Charles Griffin, London

Scarpaci C, Bigger SW, Corkeron PJ, Nugegoda D (2000) Bottlenose dolphins, Tursiops truncatus, increase whistling in the presence of 'swim-with-dolphin' tour operations. J Cetacean Res Manag 2:183-185

Silvani L, Raich J, Aguilar A (1992) Bottlenose dolphins, Tursiops truncatus, interacting with fisheries in the Balearic Islands, Spain. Europ Res Cetaceans 6:32-34

Taylor BL, Gerrodette T (1993) The uses of statistical power in conservation biology: the vaquita and northern spotted owl. Conserv Biol 7:489-500

Venables WN, Ripley BD (2000) S programming. SpringerVerlag, New York

Wells RS, Scott MD (1990) Estimating bottlenose dolphin population parameters from individual identification and capture-release techniques. Rep Int Whal Comm Spec Issue 12:407-415

Wells RS, Scott MD (2002) Bottlenose dolphins. In: Perrin WF, Würsig B, Thewissen JGM (eds) Encyclopedia of marine mammals. Academic Press, San Diego, p 122-128

Williams JA, Dawson SM, Slooten E (1993) The abundance and distribution of bottlenosed dolphins (Tursiops truncatus) in Doubtful Sound, New Zealand. Can J Zool 71:2080-2088

Wilson B, Hammond PS, Thompson PM (1999) Estimating size and assessing trends in a coastal bottlenose dolphin population. Ecol Appl 9:288-300 
Appendix 1. Derivation of detection function and line-transect abundance estimator of bottlenose dolphins Tursiops truncatus and striped dolphins Stenella coeruleoalba

\section{Derivation of detection function model}

Detection function $g(x \mid S, Z)$ was derived using a conditional likelihood (e.g. Borchers et al. 2002). We defined the probability of detecting a dolphin group at perpendicular distance $x_{i}$ given $S$, and covariates $Z_{i}$ as

$$
g\left(x_{i} \mid Z_{i}\right)=g\left(x_{i} \mid S, Z_{i}\right) \pi\left(x_{i} \mid S, Z_{i}\right) a(S, x)
$$

where $\pi\left(x_{i} \mid S, Z_{i}\right)$ is the conditional density of $x$ in the population. When transect lines are randomly placed as in this study, independence between $x$ and $Z$ can be assumed, and $\pi\left(x_{i} \mid S\right) \approx I(0 \mid W)$, i.e. $x$ is uniform between 0 and righttruncation perpendicular distance $W$. Then, Eq. (1) becomes $g\left(x_{i} \mid Z_{i}\right)=g\left(x_{i} \mid S, Z_{i}\right) W^{-1} a(S, x)$, with density function

$$
f\left(x_{i} \mid Z_{i}\right)=\frac{g\left(x_{i} \mid S, Z_{i}\right) a\left(S, x_{i}\right)}{\int_{0}^{W} g\left(x_{i} \mid S, Z_{i}\right) a\left(S, x_{i}\right) d x}
$$

The integral in Eq. (2) is $\mu\left(Z_{i}\right)$, the effective strip half-width. This parameter divided by $W$ is the average probability that an available (non-diving) dolphin group with covariates $Z_{i}$ is sighted.

By assumption, $g\left(0 \mid S, Z_{i}\right)=1$. Then, Eq. (2) can be evaluated at 0 for convenience:

$$
\hat{f}\left(0 \mid Z_{i}\right)=\frac{\hat{a}(S, 0)}{\hat{\mu}\left(Z_{i}\right)}
$$

where $f\left(0 \mid Z_{i}\right)$ can be estimated using multivariate detection function models in which covariates affect the scale parameter (e.g. Ramsey et al. 1987, Marques 2001, Forcada 2002). In our case, covariates $Z_{i}$ were assumed to have multiplicative effects of the form $\alpha_{0}\left(Z_{i}\right)=\exp \left[\alpha_{0}+\sum_{\mathrm{i}} \alpha_{\mathrm{i}} \log \left(Z_{i}\right)\right]$ in 2 competing parametric models, the hazard-rate detection function of Hayes \& Buckland (1983):

$$
g\left(x_{i} \mid S, Z_{i}\right)=1-\exp \left[\left(-\frac{x_{i}}{\alpha\left(Z_{i}\right)}\right)^{-b}\right]
$$

where $b$ is a shape parameter, and the half-normal model (e.g. Quinn \& Gallucci 1980)

$$
g\left(x_{i} \mid S, Z_{i}\right)=\exp \left[-\frac{1}{2}\left(\frac{x_{i}}{\alpha\left(Z_{i}\right)}\right)^{2}\right]
$$

\section{Derivation of Horwitz-Thompson-like line-transect abundance estimator}

Horvitz-Thompson-like (Borchers et al. 1998) line transect estimators have the general form

$$
\hat{N}=\frac{A}{a_{W}} \sum_{i=1}^{n} \frac{1}{E\left[p\left(x_{i}, Z_{i}\right)\right]}
$$

where $A$ is the area sampled and $a_{W}=2 L W$ is the area effectively surveyed, which results from combining total transect length $L$ and $W$, the maximum arbitrary strip width or righttruncation distance. Summation of the inverse detection probabilities $p$ is over the $n$ detected groups during the survey of Area $A$.

From Eqs. (1) \& (3),

$$
\begin{aligned}
E\left[p\left(x_{i} \mid S, Z_{i}\right)\right] & =W^{-1} \int_{0}^{W} g\left(x_{i} \mid S, Z_{i}\right) a\left(S, x_{i}\right) d x \\
& =W^{-1} \mu\left(Z_{i}\right) \\
& =W^{-1} \frac{a(S, 0)}{f\left(0 \mid Z_{i}\right)}
\end{aligned}
$$

Substituting in Eq. (6), the abundance of dolphin groups is

$$
\hat{N}=\frac{A}{2 L} \frac{\sum_{i=1}^{n} f\left(0 \mid Z_{i}\right)}{\hat{a}(S, 0)}
$$

and the estimators of dolphin abundance and bias-corrected mean group size are derived similarly 